\title{
Developing an Industrial Engineering Study Plan Using ISM Approach
}

\author{
https://doi.org/10.3991/ijep.v9i3.9884 \\ Murad Andejany ( $(\varpi)$ \\ University of Jeddah, Jeddah, Saudi Arabia \\ mbazzar@uj.edu.sa \\ Ahmad Elshennawy \\ University of Central Florida, Orlando, USA \\ Mohammed Darwish \\ Kuwait University, Kuwait, Kuwait \\ Haitham Bahaitham \\ King Abdulaziz University, Jeddah, Saudi Arabia \\ University of Jeddah, Jeddah, Saudi Arabia
}

\begin{abstract}
With the various developments that occur in the engineering field, it's necessary for academicians to develop appropriate curricula for engineering students. Being accredited from the Accreditation Board for Engineering and Technology (ABET) is an indication that an academic program has fulfilled international standards in engineering education. The main element in ABET evaluation process is Student Outcomes (SOs) as they incorporate several capabilities and skills expected by stakeholders such as employers. In this study, we used Interpretive Structural Modeling technique (ISM), which is a soft operational research technique, to prioritize SOs and develop a precise study plan for the Industrial Engineering program at Department of Industrial and Management Systems Engineering (IMSE) at Kuwait University (KU). This plan showed an intelligible depiction of the relationships between the SOs and a clear direction on how to merge them within the engineering study plan. For data collection, surveys were developed and conducted to faculty members at IMSE Department at KU in addition to a set of employers within the country. The results indicated that ISM model facilitates a clear understanding of the relationships among SOs within the Industrial Engineering study plan at IMSE at KU. In addition, it recommended that students should understand the professional and ethical responsibilities at early stages of the study plan and that should be followed by training them on effective communication techniques.
\end{abstract}

Keywords-Engineering education, study plan, ABET, ISM, prioritization, student outcomes, Industrial Engineering, curriculum 


\section{$1 \quad$ Introduction}

Education is one of utmost importance for any country. Country's policies and strategic management efforts of both governmental and private organizations heavily depend on excellence in each and every sector, and engineering as of today continues to play one of the most vital roles in terms of education. A teaching program to raise generations of students will only be successful if there is a curriculum that is extensive yet collaborative with world standards, and innovative yet conforming to country's cultural needs. The Accreditation Board for Engineering and Technology (ABET) is playing the role of measuring these aspects to make sure that a teaching program remains satisfactory.

In this study, the Interpretive Structural Modeling (ISM) approach is employed to create a precise study plan for the Industrial Engineering program at the Industrial and Management Systems Engineering Department (IMSE) at Kuwait University. This study is unique in terms of ISM's application to include both the Kuwait University's faculty members and key personnel from Kuwait's business companies to determine and model the relationship between Student Outcomes (SOs) and what work should be done to obtain these outcomes. By doing so, a proper alignment of a broader range of constituents needs is assumed to be obtained while designing the designated program.

\section{Previous Work}

Much effort has been devoted to ways and methodologies to promote and sustain excellent education programs to train and raise today's engineers. ABET is playing a substantial role in this prospective. This section provides studies regarding ABET activities, its SOs and the presence of ABET standards in Kuwait. In addition, it provides some basic backgrounds about the ISM approach applied in the study.

\subsection{ABET and accreditation in Kuwait}

Student Outcomes assessment has been incorporated to institutions of higher education by government funding sources, industry, and academic accreditation entities such as ABET [1]. ABET is one of the programmatic accrediting organizations recognized by the U.S. Council for higher education accreditation since 1997, with the scope of accreditation that includes several program levels, ranging from associate to masters, in engineering, engineering technology, computing, and applied science in the United States and internationally [2], [3]. It was founded in 1932 as the Engineers' Council for Professional Development (ECPD), with activities driven by the professionals it served [2]. However, today's ABET standards for the accreditation process are provided by experts from 35 member societies by which it has accredited more than 3800 programs in 31 countries [2]. In addition to accrediting programs outside the USA, ABET has an international presence through its mutual recognition agree- 
ments (MRA) and memoranda of understanding (MOU) with various international accrediting bodies [4].

Engineering programs that seek ABET accreditation are required to satisfy the following "eight criteria: students, program educational objectives, student outcomes (SOs), continuous improvement, curriculum, faculty, facilities, and institutional support" [5].

The accreditation journey takes around 20 months starting with a self-study report preparation by program seeking accreditation and ending by notifying the program with the accreditation action according to outcomes of the on-site visit conducted by the review team [6].

In Kuwait, there are $24 \mathrm{ABET}$ accredited programs in five higher education institutes. Out of these accredited programs, 13 programs offer diploma degrees in various engineering technologies, 2 offer bachelor's degree in computer science, and 9 offer bachelor degrees in various engineering disciplines [7]. 8 of the engineering and one of the computer science accredited programs are offered at Kuwait University (KU). The KU engineering programs were initially accredited in 2006. The programs are Chemical Engineering, Civil Engineering, Computer Engineering, Electrical and Electronics Engineering, Engineering Management, Industrial Engineering, Mechanical Engineering, and Petroleum Engineering. The university was established in 1966 and has 17 colleges offering various graduate and undergraduate programs. All engineering programs are currently offered by the College of Engineering and Petroleum except the Computer Engineering program which is offered by the College of Computing Science and Engineering [8].

\subsection{ABET student outcomes and curriculum design}

Despite the effective impact of ABET accreditation criteria on improving quality of engineering education on continuous manner, third criterion related to student outcomes which defined in Table 1 plays a significant role in this regard. This criterion requires undergraduate engineering programs to meet program educational objectives through satisfying a predefined set of learning outcomes given in [5].

The student outcome assessment is the primary focus of higher education institutions to measure the results of their educational programs and courses [1]. Institutions cannot have comprehensive assessment processes within their organizations without laying down structures, policies, and procedures that encourage having coherent and cross-disciplinary collaboration curricula [1]. However, developing new curricula based on specifically identified learning objectives coupled with specific outcomes the achievement of which are assessed for continuous improvement will not have a significant impact on the institution unless its other parts are properly aligned [1]. In an effort to address this, researchers discussed various aspects related to curriculum design such as:

- Amount and distribution of design content when designing engineering curricula as compared to the amount of math, basic sciences, and engineering sciences content [9] \& [10] 
Table 1. Student Outcomes for Engineering Program

\begin{tabular}{|c|l|}
\hline SOs & \multicolumn{1}{|c|}{ Explanations } \\
\hline A & An ability to apply knowledge of mathematics, science, and engineering \\
\hline B & An ability to design and conduct experiments, as well as to analyze and interpret data \\
\hline C & $\begin{array}{l}\text { An ability to design a system, component, or process to meet desired needs within realistic con- } \\
\text { straints such as economic, environmental, social, political, ethical, health and safety, manufactura- } \\
\text { bility, and sustainability }\end{array}$ \\
\hline D & An ability to function on multidisciplinary teams \\
\hline E & An ability to identify, formulate, and solve engineering problems \\
\hline F & An understanding of professional and ethical responsibility \\
\hline g & An ability to communicate effectively \\
\hline h & $\begin{array}{l}\text { The broad education necessary to understand the impact of engineering solutions in a global, } \\
\text { economic, environmental, and societal context }\end{array}$ \\
\hline i & A recognition of the need for, and an ability to engage in life-long learning \\
\hline j & A knowledge of contemporary issues \\
\hline k & $\begin{array}{l}\text { An ability to use the techniques, skills, and modern engineering tools necessary for engineering } \\
\text { practice }\end{array}$ \\
\hline
\end{tabular}

- Methods to fulfill the multidisciplinary ABET requirement with multi-, inter- or trans - disciplinary capstone design courses [11]

- Roles of faculty members and students in ABET accreditation process especially those related to developing curriculums with impeded outcomes assessment setups [1] as well as implementation of planned strategies [12]

- Considering technology-based assessment, whenever appropriate, in order to mitigate the effect of time-intensive faculty involvement with students within the outcome- based learning setup and ensure having the outcome assessment as an inherent element in curriculum development [1]

- Addressing ABET SOs through learning objectives, instructional techniques, and assessment methods of individual courses of a certain program [12]

- Methods of teaching and assessing ABET "professional skills" (also known as soft skills) such as teamwork, understanding professionalism and ethics, communication, global and social context, lifelong learning, and knowledge of contemporary issues [13] \& [14]

- Rating the importance of competencies represented within ABET SOs in the professional experience after completing an engineering undergraduate program [15]

- Integrating the "development of innovation competencies with regular engineering curriculum" to satisfy the increasingly demanded knowledge-sharing between research institutions and industry [16]

- Practices that enhance undergraduate engineering programs global preparedness [17]

- Proposing effective curriculum designs based on SOs prioritization in a way that incorporates the impeded relationships among them [18]

\subsection{Interpretive structural modelling (ISM)}

ISM is not a millennium or technological fashion to solve problems but is quite old and an extensively used model to approach decision problems, proposed firstly by $\mathrm{J}$. 
Warfield in 1973. All fundamental concepts, process to apply ISM as well as two illustrative examples may be found in [19]. The examples show how the complexity of a problem is handled by individual and group perceptions. As demonstrated by [20] in Fig 1, it is quite straightforward and easy to combine ISM with other problem solving techniques. It is a well-established methodology for identifying and summarizing relationships among specific elements, which define an issue or a problem. ISM transforms unclear, poorly articulated mental models of a system into visible well-defined, hierarchal models. Due to gradually used of the ISM methodology by various researchers, there are several studies that conducted to demonstrate the key concepts of the ISM in details [21].

ISM methodology is a proper method which used by researcher and industry manager to assist them to take optimum decisions. Likewise, there are other methods can be used for similar cases such as Analytic Hierarchy process (AHP) or Analytic Network Process (ANP). ISM involves a set of interconnected criteria, as well as it better match in this study than the other methods to address problems that are complex and subjective [22].

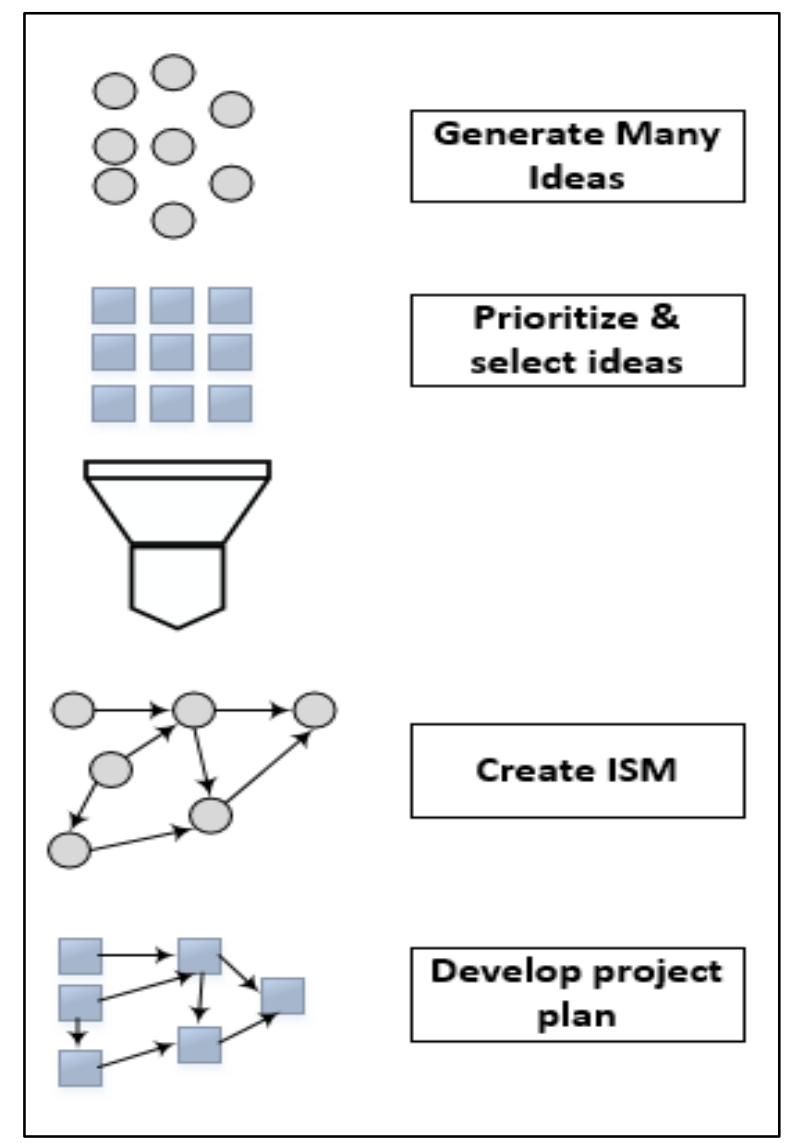

Fig. 1. High Level View of ISM Process (Adopted from:[20]) 
The ISM approach has been applied in various fields [23], [24], [25], [26] including education [27] and curriculum design [18]. In [27] ISM is used to examine the education system in India with the aim of prioritizing strategic issues in quality of education and freeing the education objectives from financial concerns, thus increasing effectiveness and accountability of education system.

In an effort to understand ABET SOs, listed in Table 1, and come up with effective curriculum designs, [18] used ISM to propose an ABET SOs prioritization scheme in a way that incorporates relationships among them. The study was conducted on an industrial engineering program at a Saudi University. The study showed the possibility of a systematic linkage between SOs and the curriculum while building the study plan systematically. The observed relationships among ABET SOs suggested exposing students to outcome (d) at an early stage while having them exposed to outcomes (b), (h), and (i) at the final stage of the study plan preceded directly by outcomes (j) and (f).

\section{Scope, Methodology and Application}

This study aims to develop a study plan of the Industrial Engineering program at IMSE Department at KU using the ISM method. In order to initiate the ISM methodology and articulate the SOs, first the Structural Self-Interaction Matrix (SSIM) of SOs is constructed by using the relationship types given in Table 2.

Table 2. Direction of the Relationships among SOs

\begin{tabular}{|c|l|}
\hline Symbol & \multicolumn{1}{|c|}{ Direction of the Relationships Among the SOs (Explanation) } \\
\hline V & For the relation from SO (a) to SO (b) (i.e., factor a will influence factor b) \\
\hline A & For the relation from SO (b) to SO (a) (i.e., factor a will be influenced by factor b) \\
\hline X & For both direction relations (i.e., SOs (a) and (b) will influence each other) \\
\hline O & For no relation between the SOs (i.e., SOs (a) and (b) are unrelated) \\
\hline
\end{tabular}

8 expert faculties from IE department in KU and 5 key personnel from Kuwait business companies have expressed their opinions using the SSIM as it is illustrated in Table 3 to obtain the initial reachability matrix of the SOs given in Table 4, after which final reachability matrix by taking into account the transitivity of SOs is obtained as it shown in Table 5.

Note that the driving power and dependence power of SOs are calculated as the sum of $1 \mathrm{~s}$ in their corresponding rows and columns, respectively, and they are calculated after ensuring transitivity of the reachability matrix. Once the matrix is finalized, it is 'leveled' based on the previous steps in order to draw the corresponding directed graph and also build an ISM based study plan with SOs. Leveling process is performed by iterations. In each iteration, if an SO's reachability set is the same as the intersection set, then that SO is labeled with the corresponding level. Level I is shown in blue color in Table 6. After that, each labeled SO is removed from reachability set, antecedent set and intersection set to proceed with the next iteration. In the next iteration in our study, since this time SOs (d), (h) and (k) have their reachability sets as same as their intersection sets, they are labeled as Level II. In a similar manner, once 
all SOs that have their reachability sets as same as their intersection sets, they are labeled until the ISM process is finished and the study plan is constructed based on annual delivery of the proposed study plan period.

Based on Table 6, SOs (a), (b), (c), (e), (i), and (j) are in Level I, SOs (d), (h), and $(\mathrm{k})$ are in Level II, SO (g) is uniquely in Level III and SO (f) is uniquely in Level IV. Since all SOs are leveled at the end of iteration 4, the process is finalized.

Table 3. The Structural Self-Interaction Matrix (SSIM) Among SOs

\begin{tabular}{|c|c|c|c|c|c|c|c|c|c|c|c|}
\hline & $\mathbf{k}$ & $\mathbf{j}$ & $\mathbf{i}$ & $\mathbf{h}$ & $\mathbf{g}$ & $\mathbf{f}$ & $\mathbf{e}$ & $\mathbf{d}$ & $\mathbf{c}$ & $\mathbf{b}$ & $\mathbf{a}$ \\
\hline $\mathrm{a}$ & $\mathrm{V}$ & $\mathrm{O}$ & $\mathrm{O}$ & $\mathrm{O}$ & $\mathrm{O}$ & $\mathrm{O}$ & $\mathrm{X}$ & $\mathrm{O}$ & $\mathrm{X}$ & $\mathrm{X}$ & \\
\hline $\mathrm{b}$ & $\mathrm{A}$ & $\mathrm{O}$ & $\mathrm{O}$ & $\mathrm{O}$ & $\mathrm{O}$ & $\mathrm{O}$ & $\mathrm{X}$ & $\mathrm{O}$ & $\mathrm{V}$ & & \\
\hline $\mathrm{c}$ & $\mathrm{A}$ & $\mathrm{O}$ & $\mathrm{O}$ & $\mathrm{O}$ & $\mathrm{O}$ & $\mathrm{O}$ & $\mathrm{X}$ & $\mathrm{O}$ & & & \\
\hline $\mathrm{d}$ & $\mathrm{O}$ & $\mathrm{O}$ & $\mathrm{O}$ & $\mathrm{O}$ & $\mathrm{V}$ & $\mathrm{V}$ & $\mathrm{O}$ & & & & \\
\hline $\mathrm{e}$ & $\mathrm{V}$ & $\mathrm{O}$ & $\mathrm{O}$ & $\mathrm{O}$ & $\mathrm{O}$ & $\mathrm{O}$ & & & & & \\
\hline $\mathrm{f}$ & $\mathrm{O}$ & $\mathrm{O}$ & $\mathrm{O}$ & $\mathrm{O}$ & $\mathrm{O}$ & & & & & & \\
\hline $\mathrm{g}$ & $\mathrm{O}$ & $\mathrm{V}$ & $\mathrm{O}$ & $\mathrm{O}$ & & & & & & & \\
\hline $\mathrm{h}$ & $\mathrm{O}$ & $\mathrm{V}$ & $\mathrm{O}$ & & & & & & & & \\
\hline $\mathrm{i}$ & $\mathrm{O}$ & $\mathrm{X}$ & & & & & & & & & \\
\hline $\mathrm{j}$ & $\mathrm{O}$ & & & & & & & & & & \\
\hline $\mathrm{k}$ & & & & & & & & & & & \\
\hline
\end{tabular}

Table 4. The Initial Reachability Matrix of SOs

\begin{tabular}{|c|c|c|c|c|c|c|c|c|c|c|c|}
\hline Sos & (a) & (b) & (c) & (d) & (e) & (f) & (g) & (h) & (i) & (j) & (k) \\
\hline (a) & 1 & 1 & 1 & 0 & 1 & 0 & 0 & 0 & 0 & 0 & 1 \\
\hline (b) & 1 & 1 & 1 & 0 & 1 & 0 & 0 & 0 & 0 & 0 & 0 \\
\hline (c) & 1 & 0 & 1 & 0 & 1 & 0 & 0 & 0 & 0 & 0 & 0 \\
\hline (d) & 0 & 0 & 0 & 1 & 0 & 1 & 1 & 0 & 0 & 0 & 0 \\
\hline (e) & 1 & 1 & 1 & 0 & 1 & 0 & 0 & 0 & 0 & 0 & 1 \\
\hline (f) & 0 & 0 & 0 & 0 & 0 & 1 & 0 & 0 & 0 & 0 & 0 \\
\hline (g) & 0 & 0 & 0 & 0 & 0 & 0 & 1 & 0 & 0 & 1 & 0 \\
\hline (h) & 0 & 0 & 0 & 0 & 0 & 0 & 0 & 1 & 0 & 1 & 0 \\
\hline (i) & 0 & 0 & 0 & 0 & 0 & 0 & 0 & 0 & 1 & 1 & 0 \\
\hline (j) & 0 & 0 & 0 & 0 & 0 & 0 & 0 & 0 & 1 & 1 & 0 \\
\hline (k) & 0 & 1 & 1 & 0 & 0 & 0 & 0 & 0 & 0 & 0 & 1 \\
\hline
\end{tabular}

Table 5. Iterations of Labeling in ISM

\begin{tabular}{|c|c|c|c|c|c|c|c|c|c|c|c|c|}
\hline SOs & (a) & (b) & (c) & (d) & (e) & (f) & (g) & (h) & (i) & (j) & (k) & Driving Power \\
\hline (a) & 1 & 1 & 1 & 0 & 1 & 0 & 0 & 0 & 0 & 0 & 1 & 5 \\
\hline (b) & 1 & 1 & 1 & 0 & 1 & 0 & 0 & 0 & 0 & 0 & 0 & 4 \\
\hline (c) & 1 & $1^{*}$ & 1 & 0 & 1 & 0 & 0 & 0 & 0 & 0 & $1^{*}$ & 5 \\
\hline$(\mathrm{d})$ & 0 & 0 & $1^{*}$ & 1 & 0 & 1 & 1 & 0 & 0 & 0 & 0 & 4 \\
\hline (e) & 1 & 1 & 1 & 0 & 1 & 0 & 0 & 0 & 0 & 0 & 1 & 5 \\
\hline (f) & 0 & 0 & $1^{*}$ & 0 & 0 & 1 & $1^{*}$ & 0 & 0 & 0 & 0 & 3 \\
\hline (g) & 0 & 0 & 0 & 0 & 0 & 0 & 1 & 0 & 0 & 1 & 0 & 2 \\
\hline (h) & 0 & 0 & 0 & 0 & 0 & 0 & 0 & 1 & 0 & 1 & 0 & 2 \\
\hline (i) & 0 & 0 & 0 & 0 & 0 & 0 & 0 & 0 & 1 & 1 & 0 & 2 \\
\hline (j) & 0 & 0 & 0 & 0 & 0 & 0 & 0 & 0 & 1 & 1 & 0 & 2 \\
\hline (k) & $1^{*}$ & 1 & 1 & 0 & $1^{*}$ & 0 & 0 & 0 & 0 & 0 & 1 & 5 \\
\hline Dependence Power & 5 & 5 & 7 & 1 & 5 & 2 & 3 & 1 & 2 & 4 & 4 & \\
\hline
\end{tabular}


Table 6. Iterations of Labeling in ISM

\begin{tabular}{|c|c|c|c|c|c|c|c|c|c|}
\hline \multicolumn{5}{|c|}{ Iteration 1-Level I (blue) } & \multicolumn{5}{|c|}{ Iteration 2-Level I crossed out and Level II (light pink) } \\
\hline Sos & Reachability Set & Antecedent Set & Intersection & Level & sos & Reachability Set & Antecedent Set & Intersection & Level \\
\hline (a) & $a, b, c, e, k$ & $a, b, c, e, k$ & $a, b, c, e, k$ & 1 & (a) & at, & k, & (k, & + \\
\hline (b) & $a, b, c, e, k$ & $a, b, c, e, k$ & $a, b, c, e, k$ & 1 & (b) & $a, b, c, e, k$ & $a, b, c, e, k$ & $a, b, c, e, k$ & + \\
\hline (c) & $a, b, c, e, k$ & $\mathrm{a}, \mathrm{b}, \mathrm{c}, \mathrm{d}, \mathrm{d}, \mathrm{e}, \mathrm{f}, \mathrm{k}$ & $a, b, c, e, k$ & 1 & $(\epsilon)$ & abce,e,k & $a, b, c, d, e, f, k$ & $a, b, c, e, k$ & + \\
\hline (d) & $c, d, f, g$ & d & d & & (d) & $\mathrm{d}, \mathrm{f}, \mathrm{g}$ & d & d & ॥ \\
\hline (e) & $a, b, c, e, k$ & $a, b, c, e, k$ & $a, b, c, e, k$ & 1 & (et) & 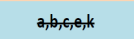 & abce,k & a, & + \\
\hline (f) & $c, f, g$ & $d, f$ & $f$ & & (f) & $f, g$ & $d, f$ & $f$ & \\
\hline (g) & $g, j$ & $d, f, g$ & $\mathrm{~g}$ & & (g) & $\mathrm{g}$ & $d, f, g$ & $\mathrm{~g}$ & \\
\hline (h) & $h, j$ & $\mathrm{~h}$ & $\mathrm{~h}$ & & (h) & $h$ & $\mathrm{~h}$ & h & ॥ \\
\hline (i) & $i, j$ & $i, j$ & $i, j$ & 1 & $H$ & H & H & H & + \\
\hline (j) & $\mathrm{i}, \mathrm{j}$ & $g, h, i, j$ & $i, j$ & 1 & H & if & hisiti & it & + \\
\hline (k) & $a, b, c, e, k$ & $a, c, e, k$ & $a, c, e, k$ & & (k) & k & k & k & $\|$ \\
\hline \multicolumn{5}{|c|}{ Iteration 3- Level II crossed out and Level III (green) } & \multicolumn{5}{|c|}{ Iteration 4- Level III crossed out and Level IV (white) } \\
\hline Sos & Reachability Set & Antecedent Set & Intersection & Level & $\underline{\text { Sos }}$ & Reachability Set & Antecedent Set & Intersection & Level \\
\hline tat & $a, b, c, k$ & ate, & ar, & + & tat & $a, b, c, e, k$ & abche,k & a,bche,k & + \\
\hline$(6)$ & $a, b, k$ & atheterk & at, & + & (b) & tot & 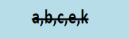 & abetek & + \\
\hline$(\omega)$ & . & (1) & , & + & $(\Leftrightarrow)$ & ; & 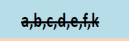 & (1) & + \\
\hline (at) & dffite & $\Leftrightarrow$ & $d$ & H & $(t+1)$ & dffis & 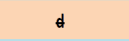 & $\#$ & $H$ \\
\hline (t) & |ה & אה, & 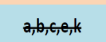 & + & tet & abcenk & abcelk & abce,k & + \\
\hline (f) & $f, g$ & f & $f$ & & (f) & f & $f$ & $f$ & IV \\
\hline (g) & g & $f, g$ & $\mathrm{~g}$ & IIII & (at) & s & $f \frac{10}{10}$ & f & $m$ \\
\hline (h) & h & h & h & H & (h) & h & h & $h$ & $H$ \\
\hline H & ij & ij & ij & + & $\mathrm{H}$ & ij & ij & ij & + \\
\hline it & Hij & ghij & in & $t$ & H & $H$ & shij & $H$ & + \\
\hline HA & * & k & k & H & $\left(H^{\prime}\right)$ & * & * & * & $H$ \\
\hline
\end{tabular}

\section{$4 \quad$ Findings}

Two important outputs are obtained based on the ISM approach applied in the study. First is the driving and dependence power diagram shown in Fig 2. Accordingly, SOs (f), (g), (h), and (i) are in the autonomous area indicating that they have comparably less driving and dependence power and may be of secondary importance in study plan design. SO (d) is independent of other outcomes but has a great driving power and is thus in independent area, while SO (j) is in close relation with other outcomes and shows a dependent relationship despite playing relatively less vital roles in study plan design. SOs (a), (b), (c), (e), and (k) are in linkage area and they are significantly important in terms of both driving power and dependence power. These SOs have correlation with other SOs and should be paid attention in order to make the best use of their driving power in the designed study plan. Among these SOs in linkage area, SO (k) has the weakest dependence power showing that it is the least dependent SO in that area, while SO (b) has the weakest driving power in area indicating that its driving power is no more than the other SOs. The analysis also shows that 
SO (c) is the most important SO that has the largest driving and dependence power among all SOs in linkage area.

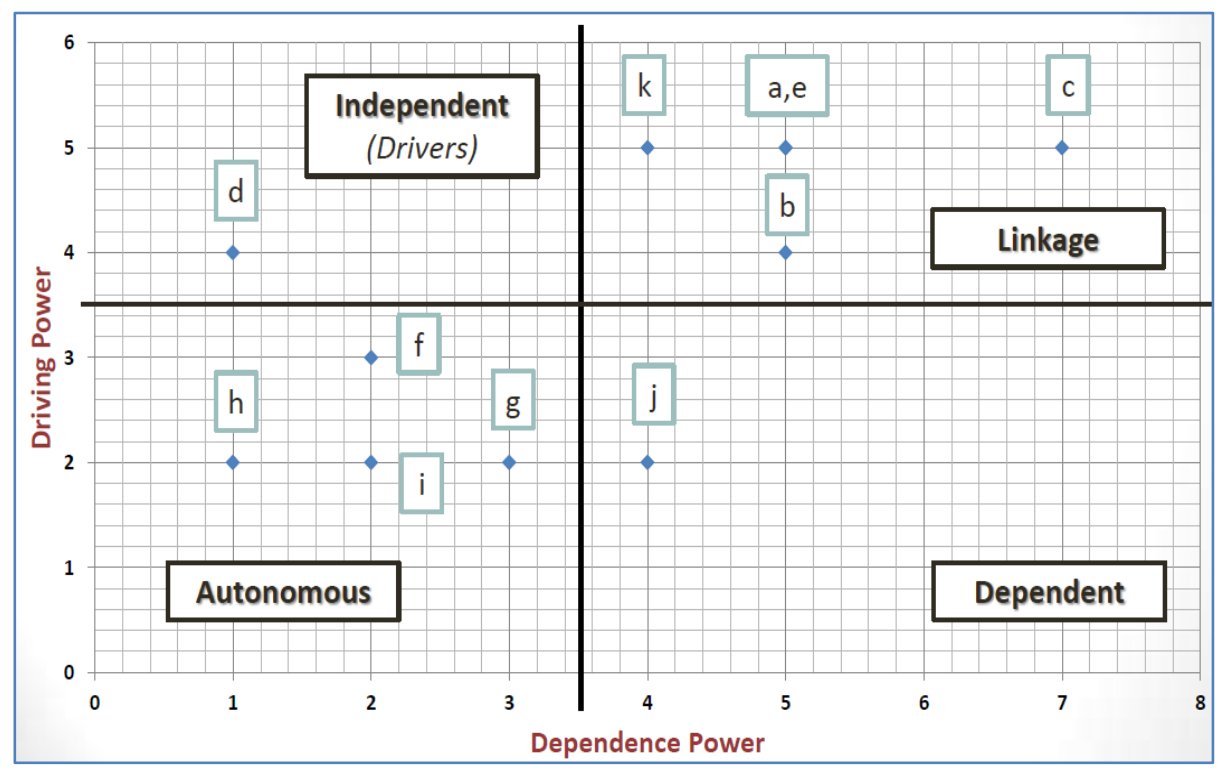

Fig. 2. Driving and Dependence Power Diagram

The second output of the ISM approach applied in the study is the proposed study plan created from prioritizing and conceptualizing all SOs. The levels at which the SOs are reflected correspond to four different levels to be considered from as it is shown in Fig 3. Accordingly, SO (f) is essential in the first level of the plan to facilitate $\mathrm{SO}(\mathrm{g})$, which will be dealt with within the context of courses taught in the second year.

In a similar manner, successes of SOs (k), (d), and (h) are affected by the achievement level of SO (g), which also affects SO (j) that located in the last level. SOs (k), (d), and (h) are linked to SOs in the fourth level of the study plan. In addition, it is shown in Fig 3 that the SOs (e),(a),(b), and (c) in the fourth level have a stronger relationships among each other which indicates that it is important to consider these SOs together in same or very close level. The unconnected SOs gives an indication of a weak or absence of relationships among them.

It is indicated that there is a lack of published articles that linked the plan of study with the ABET SOs using a scientific methodology such as ISM. However, similar study was conducted for the plan of study of the Industrial Engineering Department at King Abdulaziz University (KAU) in Jeddah, Saudi Arabia. The KAU ISM study concluded that ISM approach facilitates a clear understanding of the relationships between SOs. In addition, it indicated that "students should be trained to work in teams at the early stages of their career though the study plan, especially in the first year."[18]. Comparing both findings can provide evidences for accredited schools to prioritize the SOs and study the link among them. 


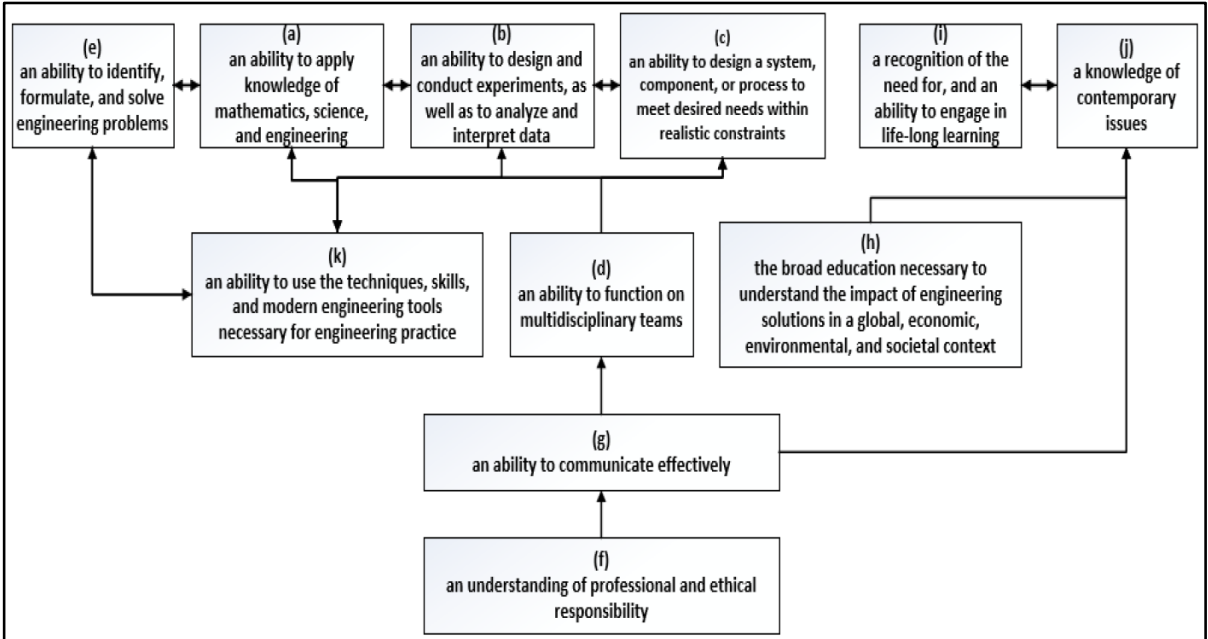

Fig. 3. Proposed Study Plan Using ISM

For instance, as we can infer from Fig 3, even if the SOs are proposed on a leveled basis and there seem to be 4 levels, it should be noted that they are not allocated to learning years, and further analysis is needed to classify them into years of education. It may be possible to start with planning of SOs starting from second year or even third year, while finishing all of the SOs within third year may also be feasible depending on the further analysis on the education system and also the SOs. This can be considered as a limitation of the study and one of the main differences between KAU ISM study and other education plans contented by the universities.

Another difference is that we provide another perspective by incorporating the data from both the Kuwait University's faculty members and key personnel from Kuwait's business companies to determine and model the relationship between Student Outcomes (SOs), and even though our sample size is not large, we are able to combine two different classes of stakeholders to design a common sense SO cluster, which is industrially different from the KAU ISM study, and which is tailored for a broader range of education periods. This in turn allows for the development of more specific programs that can include industry-based SOs in lateral phases of education program. For instance, an ability create bridges between different engineering methodologies such as operations research and $\mathrm{C \#}$ coding or a more general approach may be incorporated into SOs as a result of key sectors' requirements.

\section{Conclusion and Further Discussion}

Education is of utmost importance for any country. Country policies and strategic management efforts of both governmental and private organizations heavily depend on excellence in each and every sector, and engineering as of today continues to play one of the most vital roles in terms of education. 
In this study, industrial engineering program in Kuwait University is examined with regard to ABET SOs and their relationships as well as significance for the sake of program success using ISM approach. Even though SOs (f) and (g) seem less important as they are in the autonomous area, they are vital to achieve success in other SOs in the further years of education. Beyond this, it is seen that SOs with high dependence and driving powers are gained in the $3^{\text {rd }}$ and $4^{\text {th }}$ years of the program, and they are all linked. These SOs are, therefore, considered as objectives within the courses offered in the last two years, while communication aspects and awareness of professional and ethical responsibility are the fundamentals before starting with the technical content, and should be justified at the first two years, in order to achieve success in other desired outcomes of the program.

There are several limitations in our study which may as well be eliminated and improved in further studies. Even though our sample size contains key persons from both academic and business sectors, it is not necessarily large. There are many faculty members also many other important business companies in Kuwait, which may be included in other studies to account for a greater portion of opinions. Another aspect is related to generalization of the achieved results due to factors related to Kuwait's culture, policy and people, which significantly limit results generalization for Arabian Gulf countries or other parts of the World. It should be, therefore, kept in mind to combine ISM approach with an exact or approximate mathematical model and to increase the objectivity level and provide common-sense solution derived from multiple business sectors across multiple countries.

\section{References}

[1] L. Richards, S. Larry, C. Atman, K. Smith, Z. Jm, and B. Eschenbach, "The future of engineering education." 2002.

[2] "History | ABET." 2018.

[3] "2017-2018 Directory of CHEA-Recognized Organizations CHEA.” 2018.

[4] "Global Presence, | ABET." 2018.

[5] "Criteria for Accrediting Engineering Programs, 2016 - 2017 | ABET." 2018.

[6] "Accreditation Policy and Procedure Manual (APPM) 2017 | ABET," 2018. .

[7] "Find an ABET-Accredited Program | ABET." 2018.

[8] K. University, "Kuwait University."

[9] A. J. Dutson, R. H. Todd, S. P. Magleby, and C. D. Sorensen, "A Review of Literature on Teaching Engineering Design Through Project- Oriented Capstone Courses," J. Eng. Educ., vol. 86, no. 1, pp. 17-28, 1997. https://doi.org/10.1002/j.2168-9830.1997.tb00260.x

[10] L. Nicolai, "Viewpoint: An Industry View of Engineering Design Education," Int. J. Engng Ed, vol. 14, no. 1, pp. 7-13, 1998.

[11] K. Behdinan, R. Pop Iliev, and J. Foster, "WHAT CONSTITUTES A MULTIDISCIPLINARY CAPSTONE DESIGN COURSE? BEST PRACTICES, SUCCESSES AND CHALLENGES,” Proc. 2014 Can. Eng. Educ. Assoc. Conf., vol. 125, pp. 1-5, 2014. https://doi.org/10.24908/pceea.v0i0.5940

[12] R. Felder and R. Brent, "Designing and Teaching Courses to Satisfy the ABET Engineering Criteria," J. Eng. Educ., vol. 92, no. 1, pp. 7-25, 2003. https://doi.org/10.1002/j.21689830.2003.tb00734.x 
[13] L. J. Shuman, M. Besterfield-Sacre, and J. McGourty, "The ABET 'Professional Skills' Can They Be Taught? Can They Be Assessed?” J. Eng. Educ., vol. 94, no. 1, pp. 41-55, Jan. 2005. https://doi.org/10.1002/j.2168-9830.2005.tb00828.x

[14] O. Oviedo-Trespalacios, L. P. Angarita, M. Maestre-Meyer, and C. B. Correa, "Building the life-long learning competence in undergraduate engineering students with a laboratory practice in learning curve," Procedia - Soc. Behav. Sci. 2014, vol. 174, no. 2015, pp. 20212026, 2014. https://doi.org/10.1016/j.sbspro.2015.01.870

[15] H. J. Passow, "Which ABET Competencies Do Engineering Graduates Find Most Important in their Work?” J. Eng. Educ., vol. 101, no. 1, pp. 95-118, 2012. https://doi.org/10.1002/j.2168-9830.2012.tb00043.x

[16] R. Mathey, A. S. Reddy, and M. Shanthi, "Collaboration between Industry and Engineering Education,” J. Eng. Educ. Transform., no. Special Issue: Jan. 2015, pp. 126-132, 2015.

[17] S. Levonisova et al., "Identifying Factors That Enhance Undergraduate Engineering Students' Global Preparedness," 122nd ASEE Annu. Conf. Expo., no. Paper ID: 12356, pp. 1$18,2015$.

[18] H. Alidrisi, "Development of a Study Plan for Industrial Engineering Program Using Interpretive Structural Modeling Technique,” Int. J. Eng., 2015.

[19] D. W. Malone, "An Introduction to the Application of interpretive Structural Modeling," Proc. IEEE, vol. 63, no. 3, pp. 397-404, 1975.

[20] D. M. Lee, "Interpretive Structural Modeling (ISM)," 1988.

[21] R. Attri, N. Dev, and V. Sharma, "Interpretive Structural Modelling (ISM) approach: An Overview,” Res. J. Manag. Sci., vol. 2, no. 2, pp. 3-8, 2013.

[22] A. Jayant, M. Azhar, and P. Singh, "Interpretive Structural Modeling (ISM) Approach: A State of the Art Literature Review," IJRMET, vol. 5, no. 1, pp. 15-21, 2015.

[23] K. Mathiyazhagan, K. Govindan, A. NoorulHaq, and Y. Geng, "An ISM approach for the barrier analysis in implementing green supply chain management," J. Clean. Prod., vol. 47, pp. 283-297, May 2013. https://doi.org/10.1016/j.jclepro.2012.10.042

[24] M. Alawamleh and K. Popplewell, "Interpretive structural modelling of risk sources in a virtual organisation," Int. J. Prod. Res., vol. 49, no. 20, pp. 6041-6063, 2011. https://doi.org/10.1080/00207543.2010.519735

[25] P. Jia, A. Diabat, and K. Mathiyazhagan, "Analyzing the SSCM practices in the mining and mineral industry by ISM approach,” Resour. Policy, vol. 46, pp. 76-85, Dec. 2015. https://doi.org/10.1016/j.resourpol.2014.04.004

[26] P. S. Gour Ram Janm; Sohani, Nagendra, "Interpretive Structural Modeling of Information Sharing Barriers in Indian Manufacturing Firms,” J. Supply Chain Manag. Syst., vol. 2, pp. 26-32, 2013.

[27] N. Sohani and N. Sohani, "Developing Interpretive Structural Model for Quality Framework in Higher Education: Indian Context," J. Eng. Sci. Manag. Educ., vol. 5, no. II, pp. 495-501, 2012.

\section{$7 \quad$ Authors}

Murad Andejany, Ph.D., is an Assistant Professor in the Industrial Engineering Department at Faculty of Engineering, University of Jeddah. Currently, He is the Managing Director Assistant at King Abdulaziz University Endowments. Dr. Andejany can be contacted on mbazzar@uj.edu.sa 
Ahmad K. Elshennawy, Ph.D., is a Professor and Associate Chair in the Department of Industrial Engineering \& Management Systems at University of Central Florida, Orlando. Currently, He is the Graduate Director and can be contacted on Ahmad.Elshennawy@ucf.edu .

Mohammed Darwish, Ph.D., is an Associate Professor in the Industrial \& Management Systems Engineering Department at Kuwait University. Dr. Darwish can be contacted on m.darwish@ku.edu.kw .

Haitham Bahaitham, Ph.D., is an Assistant Professor in the Industrial Engineering Department at Faculty of Engineering, King Abdulaziz University - Rabigh. Currently, He serves as the Dean of Community College at University of Jeddah. Dr. Bahaitham can be contacted on hbahaitham@uj.edu.sa .

Article submitted 2018-11-19. Resubmitted 2019-02-15. Final acceptance 2019-02-16. Final version published as submitted by the authors. 